\title{
Mesophase Evolution in Heat-Treated Solid Petroleum Pitches
}

\author{
Antonio L. dos Santos Lima, ${ }^{*, a}$ Keila dos Santos C. Lima, ${ }^{a}$ Tanos C. C. França, ${ }^{a}$ \\ Maria Inês B. Tavares, ${ }^{b}$ Rosane A. da Silva San-Gil, ${ }^{c}$ Marcos N. Eberlin ${ }^{d}$ and \\ Angelo C. Pinto ${ }^{c}$
}

\author{
${ }^{a}$ Departamento de Engenharia Química, Instituto Militar de Engenharia,
} Praça General Tibúrcio, 80, 22290-270 Rio de Janeiro-RJ, Brazil

${ }^{b}$ Instituto de Macromoléculas, CT, Bloco J, and 'Instituto de Química, CT, Bloco A, Universidade Federal do Rio de Janeiro, Av. Horácio de Macedo, 2030, 21941-598 Rio de Janeiro-RJ, Brazil

'Instituto de Química, Universidade Estadual de Campinas, CP 6154, 13083-970 Campinas-SP, Brazil

\begin{abstract}
Uma combinação de técnicas analíticas foi utilizada para acompanhar a evolução da mesofase em pixes de petróleo em fase sólida. As amostras foram caracterizadas por dessorção a laser assistida por matriz, seguida de espectrometria de massas por tempo de vôo (MALDI-TOF-MS), ressonância magnética nuclear de ${ }^{13} \mathrm{C}\left({ }^{13} \mathrm{C} \mathrm{NMR}\right)$ de alto campo, ${ }^{1} \mathrm{H}$ NMR de baixo campo, ressonância eletrônica de spin (EPR), microscopia ótica polarizada e análise termogravimétrica (TGA). A análise por MALDI-TOF-MS revelou uma distribuição oligomérica de pesos moleculares no pixe: monomérica $(\mathrm{m} / \mathrm{z}, 200$ a 400), dimérica $(\mathrm{m} / \mathrm{z}, 400$ a 650), trimérica $(\mathrm{m} / \mathrm{z}, 650$ a 950$)$ e tetramérica $(\mathrm{m} / z, 950$ a 1600), fator essential para a produção de fibras de carbono, bem como outros compósitos de carbono. Estudos de tempo de relaxação $\left(\mathrm{T}_{1}\right)$ permitiram a observação de duas grandes áreas: a dos aromáticos e a de mesofase. Estes resultados também mostraram que o tempo de aquecimento aumenta a área de mesofase. Através de medidas não destrutivas de ${ }^{13} \mathrm{C} \mathrm{NMR}$, foram obtidos os conteúdos de carbonos aromáticos e alifáticos, e também o grau de protonação desses carbonos. A microscopia ótica com luz polarizada mostrou as interfaces entre as regiões anisotrópicas e isotrópicas, bem como o processo de coalescência da mesofase. Os resultados obtidos pelas outras técnicas corroboram com os resultados de MALDI-TOF-MS e NMR.
\end{abstract}

A combination of analytical techniques was used to follow the mesophase evolution of petroleum pitches in the solid phase. The samples were characterized by matrix assisted laser desorption and time of flight analysis by mass spectrometry (MALDI-TOF-MS), high field ${ }^{13} \mathrm{C}$ nuclear magnetic resonance $\left({ }^{13} \mathrm{C} \mathrm{NMR}\right)$, low field ${ }^{1} \mathrm{H} \mathrm{NMR}$, electron spin resonance (EPR), polarized optical microscopy and thermogravimetric analysis (TGA). MALDI-TOF-MS revealed an oligomeric distribution of molecular weights in the pitch: monomeric ( $\mathrm{m} / \mathrm{z}, 200$ to 400), dimeric ( $\mathrm{m} / \mathrm{z}, 400$ to 650$)$, trimeric ( $\mathrm{m} / \mathrm{z}, 650$ to 950$)$ and tetrameric $(\mathrm{m} / \mathrm{z}, 950$ to 1600), an essential factor for the production of carbon fibers, among other advanced composite of carbon. Relaxation time $\left(\mathrm{T}_{1}\right)$ studies permitted to observe two large areas: the aromatics and the mesophases. These results also showed that the heating time increases the mesophasic area. Also through direct and non-destructive ${ }^{13} \mathrm{C}$ NMR measurements, we obtained the content of aromatic and aliphatic carbons, as well as the degree of protonation of these carbons. Optical microscopy with polarized light showed the interfaces between the anisotropic and isotropic regions as well as the process of coalescence of mesophase. The results obtained by the other techniques corroborate the MALDI-TOF-MS and NMR results.

Keywords: mesophase evolution, heat-treated solid petroleum pitches, MALDI-TOF-MS, NMR, electron spin resonance, polarized optical microscopy, thermogravimetric analysis

*e-mail: santoslima@ime.eb.br 


\section{Introduction}

The demand for petroleum products has faced an accelerated growth in recent decades, demanding an increase in the operating capacity of the refineries. The consequent accumulation of residue from distillation and cracking of crude petroleum also creates a serious waste disposal problem. Fortunately, the commercial use of this petroleum waste has also increased, mainly for the production of carbon artifacts. ${ }^{1}$

Petroleum pitches are formed through polymerization of polycondensated aromatic molecules from the catalytic cracking of petroleum distillates. This polymerization reaction can produce molecules with molecular weights ranging from about 200 to $2000 \mathrm{Da},^{2-4}$ or bigger. ${ }^{5-7}$

The use of petroleum pitches as raw materials for advanced carbon artifacts requires knowledge of its composition and the existing molecular interactions. ${ }^{2,4}$ The molecular composition affects the physical properties of the pitch, such as softening point and viscosity, and the physical characteristics of the final products. For example, in the production of carbon fibers, differences in composition can modify the tensile strength, the Young's modulus and/or the thermal conductivity of the final product. ${ }^{3,8}$ The origin of the raw material also influences the chemical composition and the structures of the molecules present. ${ }^{9}$

The determination of the molecular composition of thermally treated pitches has been a continuous challenge and there are several works on literature regarding this matter since the eighties. ${ }^{10-32}$ The techniques for separation of high molecular weighted pitches, such as gel permeation chromatography and liquid chromatography, have some disadvantages, such as low resolution, incomplete solubilization of the sample, molecular weight limitations and the lack of appropriate calibration standards. ${ }^{33}$ The pitch produced for a given application should have a controlled molar weight distribution, similar to the manufacturing of polymeric products. ${ }^{34}$ Studies with insoluble samples of polymers and petroleum products in the solid state, using matrix assisted laser desorption and time of flight analysis by mass spectrometry (MALDI-TOF-MS), have shown promising results in their structural elucidation. Although the mechanical properties and performance of these materials can be properly determined, the characterization at the structural level is still a challenge. In this regard, studies of nuclear magnetic resonance (NMR) in solid state and MALDI-TOF-MS have shown promising results in the analysis of insoluble samples of pitches and coal with high molecular weight.

The literature reports an increase in the world demand for carbon materials because of their unique characteristics and diverse fields of application, such as electrical and heat conductivity (conductors and semiconductors), energy storage (anode batteries, super capacitors and gas storage), environmental protection (activated surfaces), materials for special uses (carbon fibers, composites and graphite), among others.

Thus, this study aimed to monitor, through several analytical techniques for liquids and solids, the structural changes, the polymerization and polycondensation of heat-treated petroleum derivatives toward the obtaining of raw materials for the manufacturing of high performance compounds.

\section{Experimental}

\section{Sample preparation}

The pitch was heated up to $430{ }^{\circ} \mathrm{C}$ for $4 \mathrm{~h}$ in inert gas $\left(\mathrm{N}_{2}\right)$ inside a $1 \mathrm{~L}$ reactor at $0.1 \mathrm{~Pa}$. The samples were removed when the temperature reached $430{ }^{\circ} \mathrm{C}$ (sample A) and at every 30 min afterward (samples B-I).

Sample I was subjected to centrifugation at $400{ }^{\circ} \mathrm{C}$ and then placed in a ceramic oven with capacity for 12 samples. The sample holders, with $5 \mathrm{~mL}$ of capacity, received about $3 \mathrm{~g}$ of powdered pitch (\# $60 \mathrm{mesh}$ ) each.

Optical microscopy using polarized light was used to sub-classify the samples as superior or inferior (samples $\mathbf{J}$ and $\mathrm{K}$, respectively) according to the change in the texture of the material. ${ }^{35}$

The samples were submitted to a rigorous heat treatment in order to monitor the formation of mesophases, polymers, polycondensations and rearrangements that make them partially soluble or insoluble in several organic solvents.

Former studies ${ }^{36-40}$ suggest that when compounds, to be identified by MALDI, present problems with solubility, miscibility or segregation during crystallization, a matrix should be mixed with the analyte in the solid state with subsequent application, directly or in suspension, in the cell equipment (sample holder). Therefore, there were employed two different methods for sample preparation without solvents. The first sample was powdered in glass jars by shaking small steel balls in the presence of the matrix (1:5, analyte:matrix) for $60 \mathrm{~s}$. The second sample was powdered following the same methodology, but without the matrix, and subsequently introduced into the spectrometer. The methodology for sample preparation, using grinding and mixing with steel balls, allowed the quick and efficient preparation of pitches of several softening points. ${ }^{40}$

The matrix used was 7,7,8,8-tetracyanoquinodimethane (TCNQ), which is characterized as being a strong electron acceptor, having good absorption at $337 \mathrm{~nm}$ and promoting 
a mild formation of radical cations of polycyclic aromatic molecules, preventing unwanted fragmentation. ${ }^{33,37-39,41}$ According to Edwards et al., ${ }^{33}$ the content of the matrix/pitch used in their study did not significantly affect the results. Thus, we chose the ratio 1:5 (analyte:matrix), the lowest studied. The samples were not doped with cationic agents.

\section{Analysis}

\section{MALDI-TOF-MS}

The samples for laser ionization and desorption were prepared from aliquots of pitches obtained along the heat treatment and centrifugation and were mixed to a matrix of TCNQ in a 1:5 ratio, respectively.

The mixing process was performed in glass vials containing pitch, the matrix and small steel balls. These vials were strongly agitated in a shaker for homogenization. ${ }^{17}$ Pitches without matrix were also submitted to the same process of grinding and homogenization. Homogenized samples, with and without matrix, were placed into the sample holder of the laser desorption and ionization device with MALDI-TOF-MS. ${ }^{33}$ The equipment used in these experiments was a Waters Micromass MALDI-TOF spectrometer. Desorption of the analytes was performed with a $\mathrm{N}_{2}$ laser at $337.1 \mathrm{~nm}$ with computed attenuation and a maximum power of $40 \mathrm{~kW}$. The reflexive mode was employed for analysis. ${ }^{33}$

\section{NMR}

The relaxometry measures by ${ }^{1} \mathrm{H}$ NMR were performed in a Maran Ultra $23 \mathrm{NMR}$ analyzer operating at $23.4 \mathrm{MHz}$ (for protons) and equipped with a variable temperature probe of $18 \mathrm{~mm}$ as described by Lima et al. ${ }^{42}$

The longitudinal relaxation time $\left(\mathrm{T}_{1} \mathrm{H}\right)$ was measured with the pulse sequence of inversion-recovery $\left(D_{1}-\pi-\tau-\pi / 2\right.$ acquisition), using a recycle time value greater than $5 \mathrm{~T}_{1}$ (e.g. $D_{1}$ of $10 \mathrm{~s}$ ) and pulse of $\pi / 2$ of $4.5 \mu \mathrm{s}$, automatically calibrated by the software of the equipment.

The free induced decay (FID) amplitude was set to $20 \tau$ points, ranging from 0.1 to $5000 \mathrm{~ms}$, with four accumulations each. The $T_{1}$ values and their relative intensities were obtained by the WINFIT program with the data fitting by exponential functions. The distributions of exponential fits (amplitude of relaxation) by the relaxation time were plotted using the WINDXP, and $\mathrm{T}_{1} \mathrm{H}$ relaxation data were obtained at $300 \mathrm{~K}$.

Solid state ${ }^{13} \mathrm{C}$ NMR experiments were performed on a Bruker DRX300 spectrometer, operating at $75.4 \mathrm{MHz}$ (7.05 T), with MAS, high power ${ }^{1} \mathrm{H}$ dipolar decoupling (HPDD) and ${ }^{1} \mathrm{H}-{ }^{-13} \mathrm{C}$ cross polarization (CP) using a $4 \mathrm{~mm}$ Bruker probe and rotors spinning at $5.3 \mathrm{kHz}$. Spectra were acquired with optimized contact time of $5 \mathrm{~ms}$. Repetition times $\left(\mathrm{D}_{1}\right)$ of 7.5 and $500 \mathrm{~s}$ were used in the $\mathrm{CP}$ and HPDD spectra, respectively. Interrupted decoupling experiments for non-quaternary signal suppression with cross polarization (CPNQS) were carried out by gating off the decoupler before the ${ }^{13} \mathrm{C}$ free induction decay acquisition time. The decoupler was turned on again during the acquisition period. The delay between the last pulse and acquisition time allows the dephasing delay to vary from 0 to $500 \mathrm{~ms}$. In the CPNQS experiments the rate of dephasing of the ${ }^{13} \mathrm{C}$ signal is related to the magnitude of dipolar interaction, which depends on geometrical factors, namely, the ${ }^{1} \mathrm{H}-{ }^{13} \mathrm{C}$ internuclear distance, and the angle between the internuclear vector and the static magnetic field. So in the spectra with short dephasing times, a mixture of protonated and non-protonated carbons must be detected while in the spectra with long dephasing times, the signals observed are mainly due to weakly and/or non-protonated carbons. The reference used for chemical shifts was the $\mathrm{CH}_{3}$ signal of tetrakis(trimethylsylil)silane at $2 \mathrm{ppm}$, present in all samples.

\section{Electronic magnetic resonance (EMR)}

The electron spin resonance measurements were performed at room temperature in a Varian E-12 spectrometer working at the $\mathrm{X}$ band $(9.5 \mathrm{GHz})$ with a modulation frequency of $100 \mathrm{kHz}$. The working power was $2 \mathrm{~mW}$, and the modulation amplitude was $0.1 \mathrm{mT}$. The standard used to estimate the spin concentration was named "strong pitch" from Varian ( $\mathrm{KCl}$ diluted in pitch), with a spin concentration of 1013 spins $\mathrm{cm}^{-1}$.

\section{Optic microscopy}

Representative samples of each pitch were taken from a single mass of pitch irregularly fragmented in order to produce pieces of variable sizes. The fragments were manually polished with silicon carbide sandpaper (mark Buehler, number 240) to create a flat surface prior to the inlay and to adjust the dimensions of the pieces to about 2.5 and $3.8 \mathrm{~cm}$ in diameter.

The inlay was made with the slow healing epoxy resin Epoxicure (Buehler) and $24 \mathrm{~h}$ were allowed between inlay and sanding. Then, there were performed five steps of sanding using silicon carbide sand papers (mark Buehler, numbers $240,320,400,600$ and 800 ). Water filtered through a foam filter and directly tipped on the samples was used as coolant. Between sandings, the embedded samples were washed twice. The first time with tap water from the foam filter and the second time with distilled water. After rinsing, samples were examined under a microscope to check if the scratches associated with the former sanding had been replaced by the scratches from the sanding in progress. 
Polishing was manually done in two steps: the first with cloth type texmet and an aqueous solution of $30 \mu \mathrm{m}$ diamond. The second one was performed with a microcloth cloth and a solution of $0.040 \mu \mathrm{m}$ colloidal silica mark. Except for the silica solution, which was manufactured by Struers, polishing cloths and the $3 \mu \mathrm{m}$ solution were from Buehler. Between polishing, samples were washed twice, once with tap water from the foam filter and a second time with distilled water. After rinsing, samples were examined under a microscope to monitor the progression of the polishing.

Microscopic observation with polarized light was performed in a microscope OLYMPUS PME-3, with increments of 50x, 100x, 200x and 500x and halogen light source of $100 \mathrm{~W}$ of potency. It was also used filter $\lambda / 2$ in order to accentuate the contrast between phases.

\section{Termogravimetric analysis (TGA)}

TGA analyses were performed with thermogravimetry (TG) equipment from Shimadzu, model TGA 50 under argon flow $\left(1.2 \mathrm{~L} \mathrm{~h}^{-1}\right)$. The analysis procedure consisted of heating samples $(10 \mathrm{mg})$ from room temperature to $1173 \mathrm{~K}$ at a rate of $20 \mathrm{~K} \mathrm{~min}^{-1}$.

Obtention of insoluble fractions in quinolein, toluene and $\mathrm{N}$-methyl-pirrolidinone

The acquisition of insoluble fractions of each sample of pitch in quinoline, toluene and N-1-methyl-2-pyrrolidinone followed the recommendations in ASTM D2318, ASTM D4312 and Torregrossa-Rodriguez et al., ${ }^{43}$ respectively.

\section{Results and Discussion}

\section{Studies by MALDI-TOF-MS}

Considering the broad molecular weight distribution of the pitches, it was possible to take advantage of the low molecular weight molecules as matrices. ${ }^{37,44}$ According to Przybilla et al. ${ }^{37}$ the polyaromatics up to $2000 \mathrm{Da}$ (which is the range of interest of our research) can be analyzed with no matrices, without inducing fragmentation in the laser desorption and ionization processes.

Figure 1 shows two typical mass spectra of the same pitch. The first was obtained without a matrix and the second with a matrix. They can be separated into four regions, according to the oligomeric nature presented: monomers from $\mathrm{m} / \mathrm{z}, 200$ to 400 , dimers from $\mathrm{m} / \mathrm{z} 400$ to 650 , trimers from $\mathrm{m} / \mathrm{z} 650$ to 950 and tetramers from $\mathrm{m} / \mathrm{z} 950$ to 1600 . These results are in accordance with those previously reported by Edwards and Thies. ${ }^{38,39,41}$ The results from Marzec ${ }^{45}$ also showed a bimodal distribution of masses for coal, with regions between $\mathrm{m} / \mathrm{z}$ 130-600 and 1300-3500.

The aim of employing the two methods of sample preparation described was to identify and correlate possible phenomena of coalescence and fragmentation of the samples in the processes of desorption, ionization, separation and

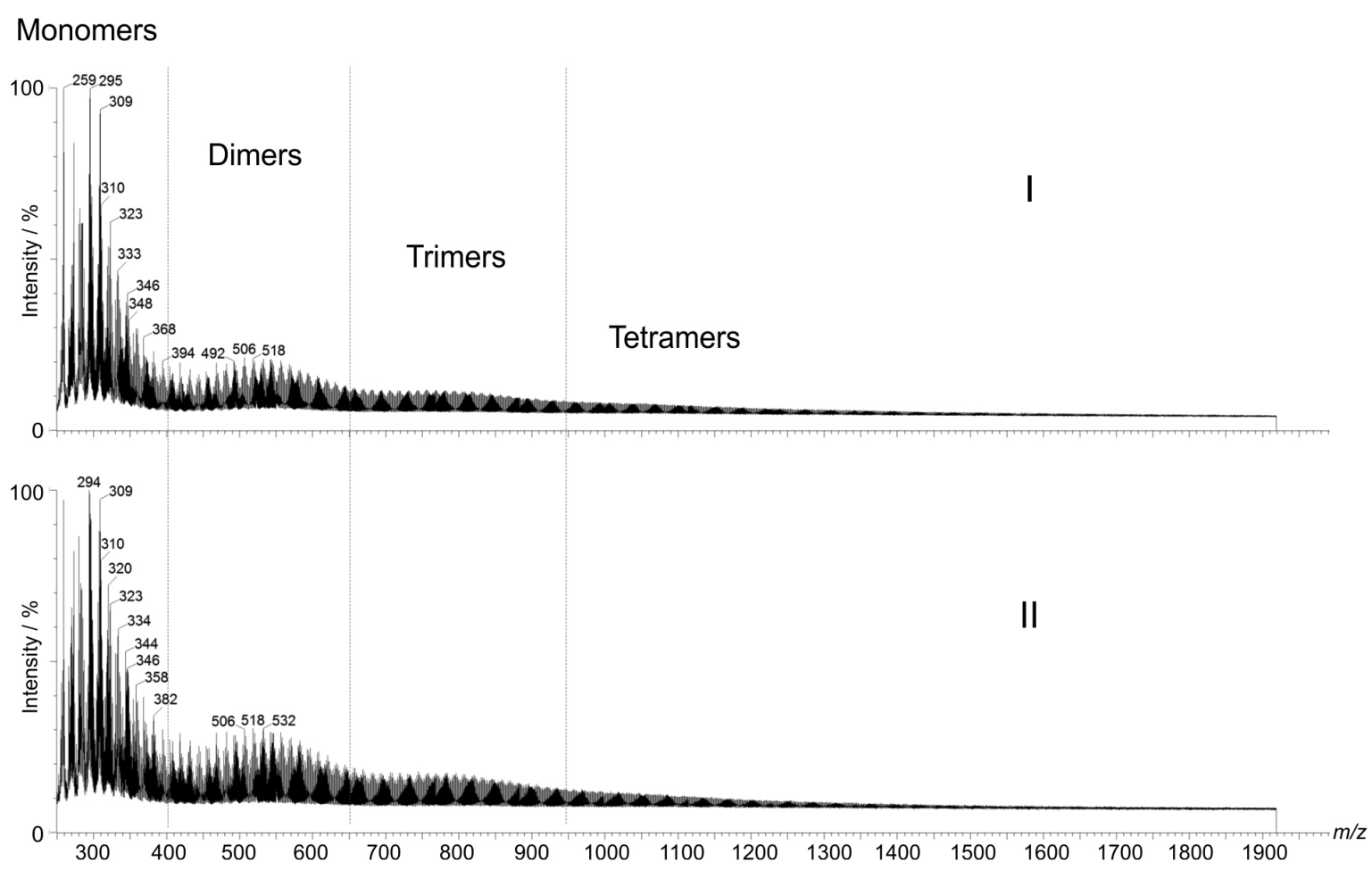

Figure 1. Mass spectra of pitch A: without matrix (I) and with matrix (II). 
identification. The mass spectra of the analyzed pitches (Figure 2) show that the addition of matrix increased the signal intensities as the molecular weight increased and also improved the signal to noise ratio. This was achieved without interference in the sample compositions once the same molecular ions identified in a matrix-free sample could be seen in the MALDI spectra. The processing time of the pitches directly influenced the regions highlighted earlier. It can be seen in the mass spectra for pitches A and I, with and without matrix, that the relative intensities of the signals of the second, third and fourth regions related to the first, increase with the time of heating (Figure 2).

The first region contains the lower limit $(\mathrm{m} / \mathrm{z}, 200)$ delineated by Edwards et $a l .{ }^{33}$ that verified the possibility of volatilization of low molecular weight species under the vacuum of the equipment $\left(10^{-6}\right.$ Torr, at $\left.25^{\circ} \mathrm{C}\right)$, also avoiding possible fragments from other molecules. Figure 3 shows the two mass spectra of the pitch at the region from $\mathrm{m} / z 200$ to 400 .
Spectra in Figure 3 show the more intense signals, probably belonging to aromatic compounds containing heteroatoms (e.g., nitrogen) and indicating the preferential ionization of these molecules. The possible structures of molecular ions present in this region are composed of four aromatic rings, heteroatoms and aliphatic side chains. The spectra also present discrete groups of ions that differ from each other by a methyl group. Nitrogen can be on the aromatic rings or on the side chains as $\mathrm{NH}_{2}$. The second region includes the fragments from $\mathrm{m} / \mathrm{z} 400$ to 650 , as shown in Figure 4.

Analysis of the spectra in Figure 4 shows that the possible structures are dimers with molecular ions smaller than $m / z$ 400. The structures present eight condensed aromatic rings and may contain two nitrogen atoms or structures with $\mathrm{NH}_{2}$. This region contains a larger number of signals, probably due to the possible combinations of monomers present in the first region, resulting in a decrease in the intensities of the molecular ions. The presence of
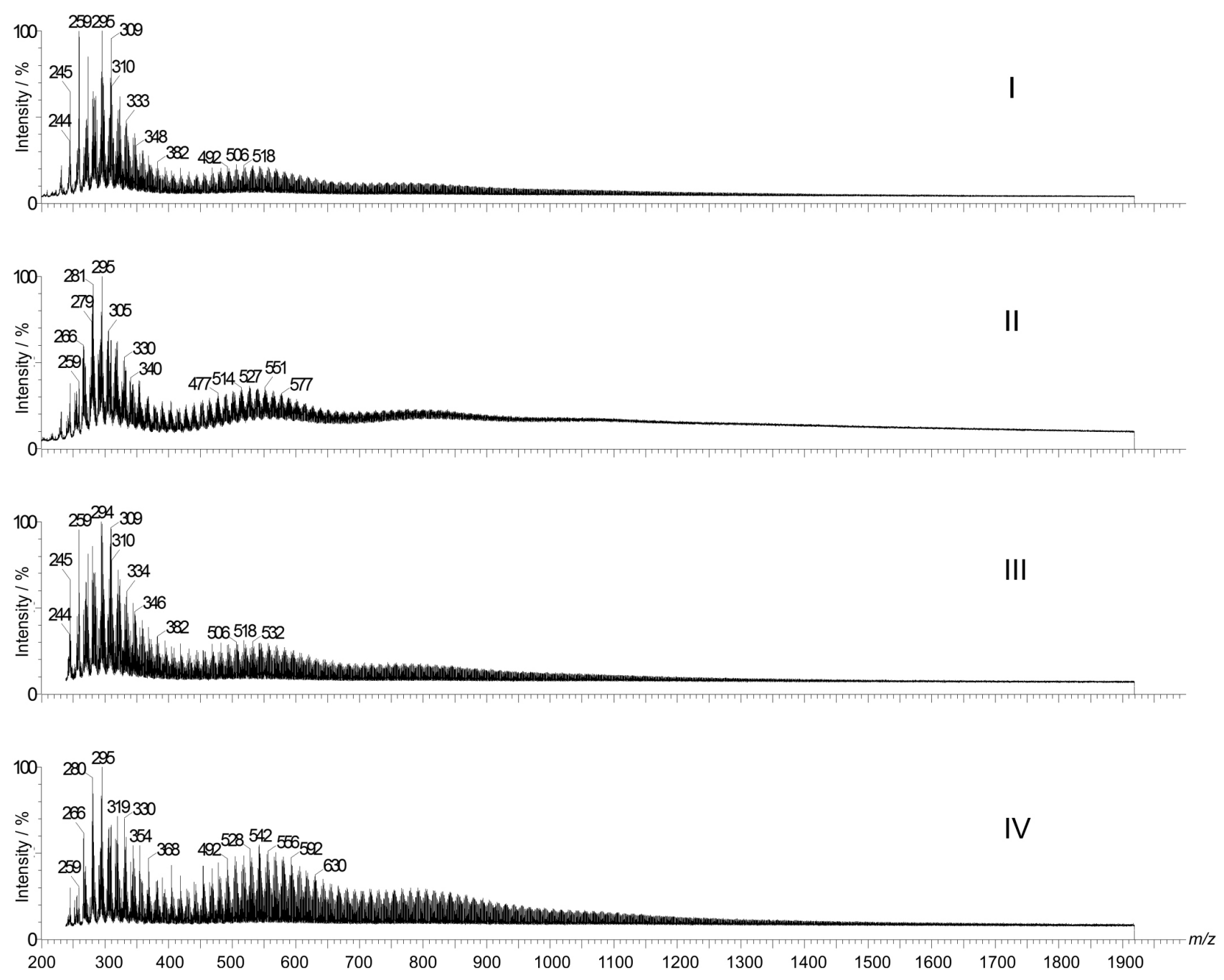

Figure 2. Mass spectra of the pitches: (I) A - without matrix; (II) I - without matrix; (III) A - with matrix; (IV) I - with matrix. 

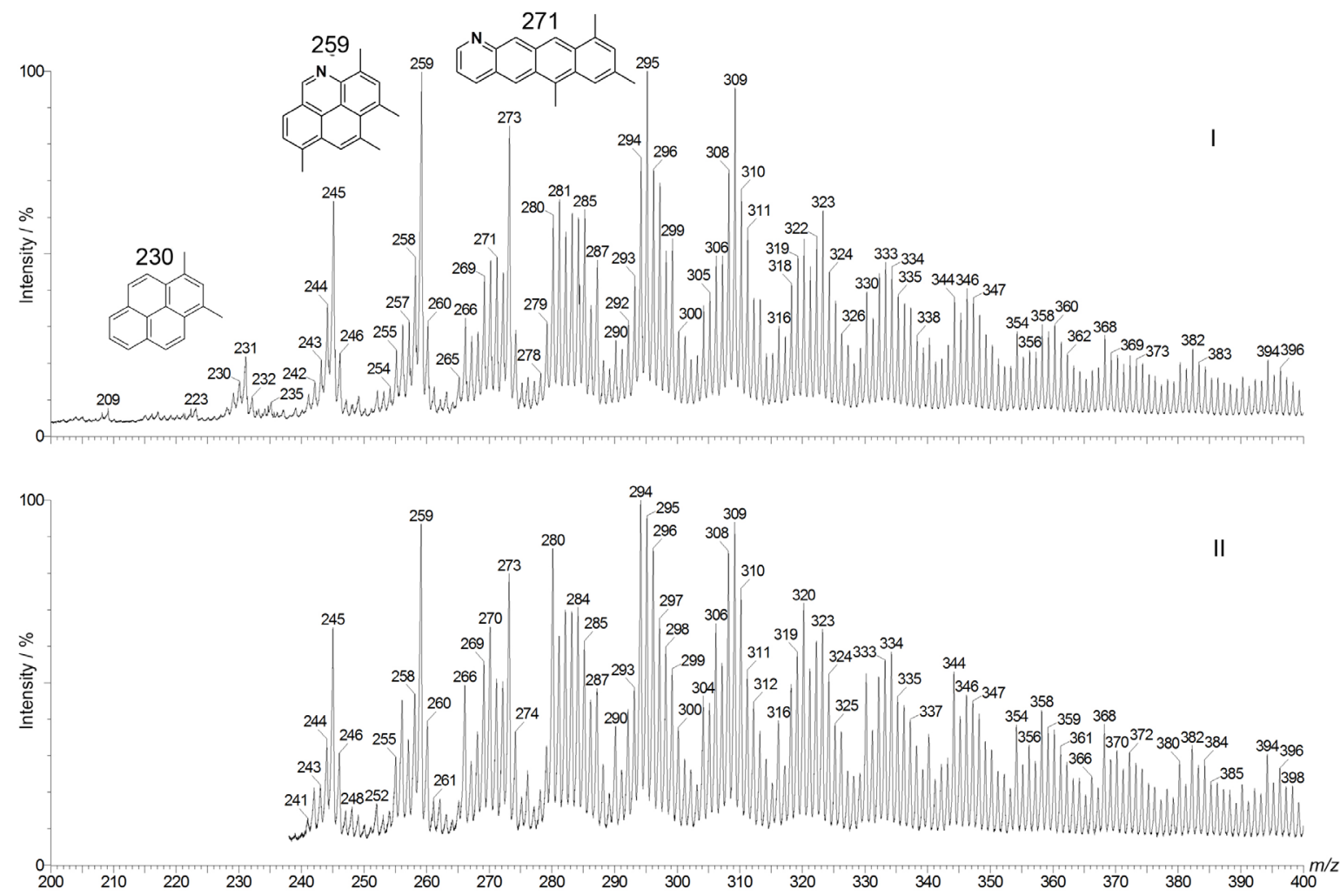

Figure 3. Mass spectra of picht A, without matrix (I) and with matrix (II) in the range from $m / z 200$ to 400 .

side chains on the aromatic rings of monomers favors polycondensations with more linear structures, increasing the chances for isomers in the signal observed.

The third area studied is represented by the pitch I in the spectra of Figure 5. In this figure, it can be seen molecular structures containing 12 substituted aromatic rings, with or without nitrogen, as indicated.

Figure 6 shows the mass spectrum of the molecular ions present in the fourth region of the pitch I, with and without matrix. Possible molecular structures present contain 16 substituted aromatic rings, with or without nitrogen. The signals in the spectrum of pitch I returned to the baseline at approximately $\mathrm{m} / \mathrm{z} 1600$. These results show that heat treatment could have been extended, once the larger masses found are below those reported in the literature. ${ }^{36,46,47}$

In the third and fourth regions, between $\mathrm{m} / \mathrm{z}, 650$ and 1600 , it was observed that the addition of the matrix TCNQ improved the resolution and strength of the signals. The structures observed in each region are examples of possible molecules present in the pitches studied, and serve as a model to explain the reactions of polymerization and polycondensation of these materials. Data obtained by mass spectrometry showed that the aromatic molecules in the decanted petroleum may lead to the possible structures suggested for the pitches A-I, by polymerization and polycondensations. Mochida et al..$^{48}$ reported some structures of mesogenic compounds after catalytic polymerizations and heat treatment from different monomers, confirming the proposed structures.

Magnetic resonance

\section{NMR - low field}

The importance of the mesophase has motivated several studies on its characterization. Several studies have been reported on pitches from petroleum and tar using gas and liquid chromatographies, X-ray diffraction, ${ }^{13} \mathrm{C}$ and ${ }^{1} \mathrm{H}$ NMR, mass spectrometry, optical and electronic microscopy and insoluble fractions in several solvents. ${ }^{1,3,8,49,50}$ The quantification of the liquid crystal mesophase has been performed by optical microscopy assays with polarized light (POM) and by differences in solubility in organic solvents. ${ }^{1,3,43}$

Li et al. ${ }^{51}$ concluded that POM is not a good method to analyze the size and distribution of the mesophase spheres in an isotropic matrix of heat-treated pitches because of the random distribution. This methodology assumes only statistical results because different apparent sizes of mesophase spheres are measured, mainly caused by the random position of the spheres and the cutting plan for preparing and inlaying them for further observation. 

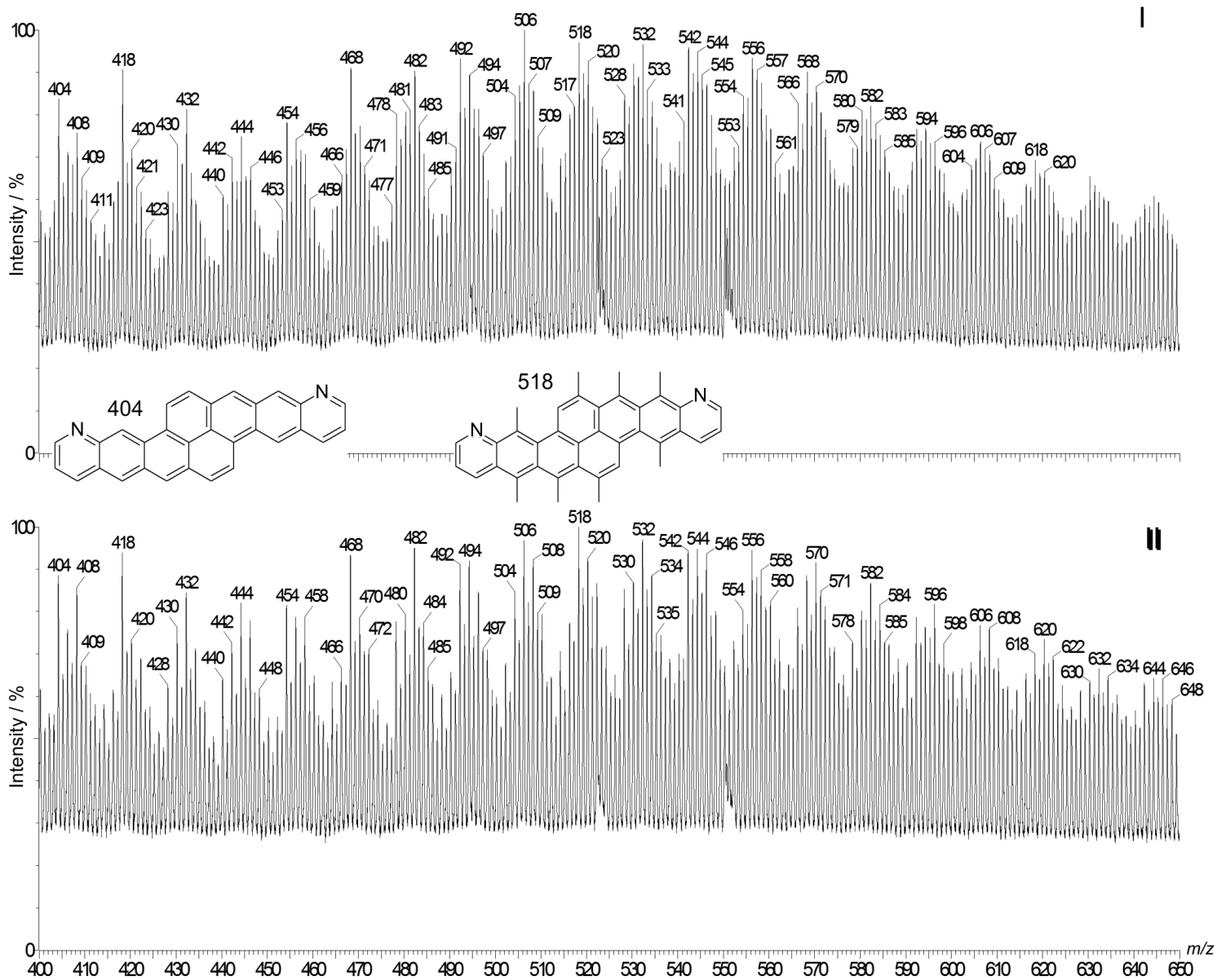

Figure 4. Mass spectra of pitch A, without matrix (I) and with matrix (II) in the region from $\mathrm{m} / \mathrm{z} 400$ to 650 .

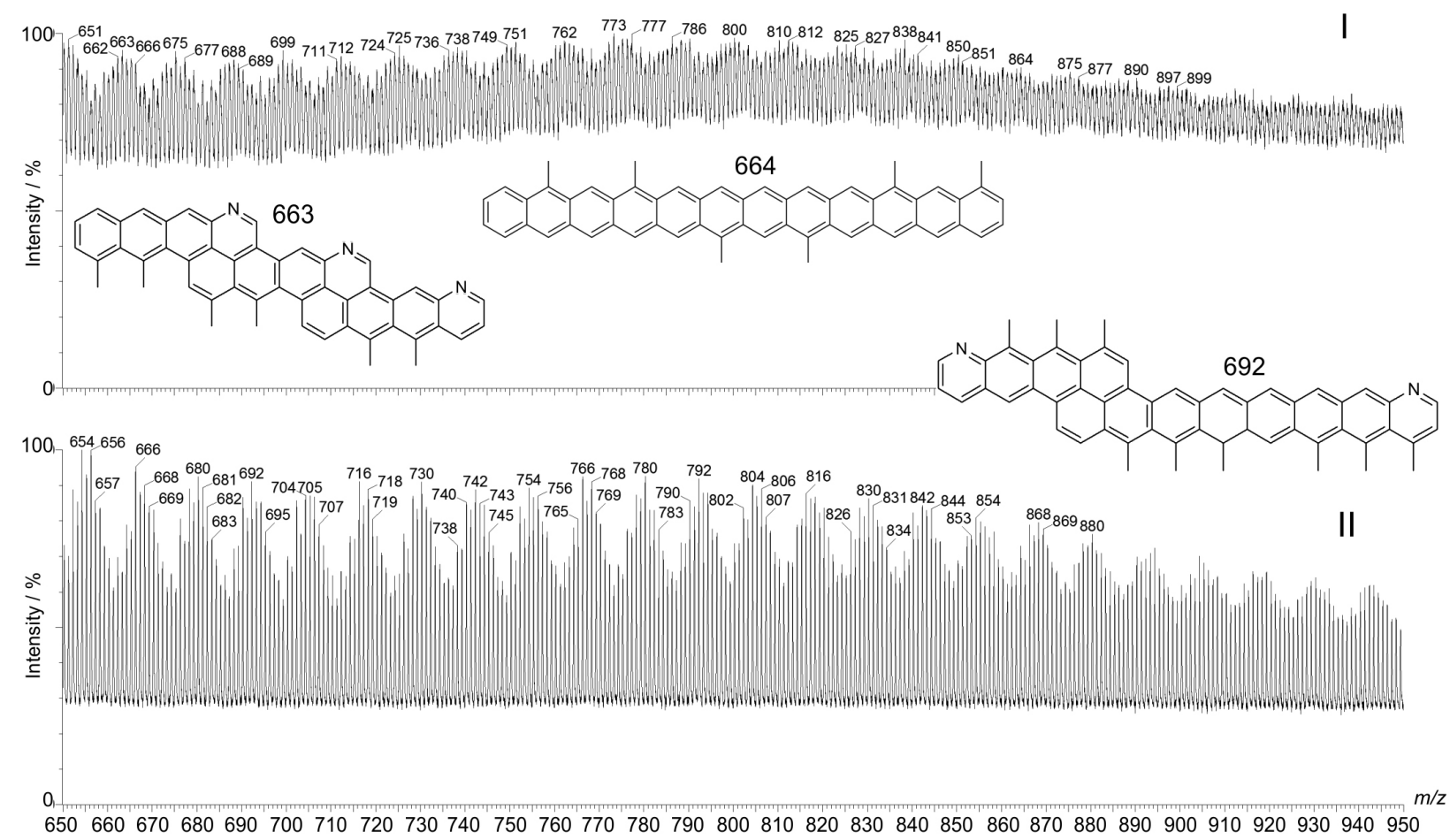

Figure 5. Mass spectra of pitch I, without matrix (I) and with matrix (II) in the region from $\mathrm{m} / \mathrm{z} 650$ to 950 . 

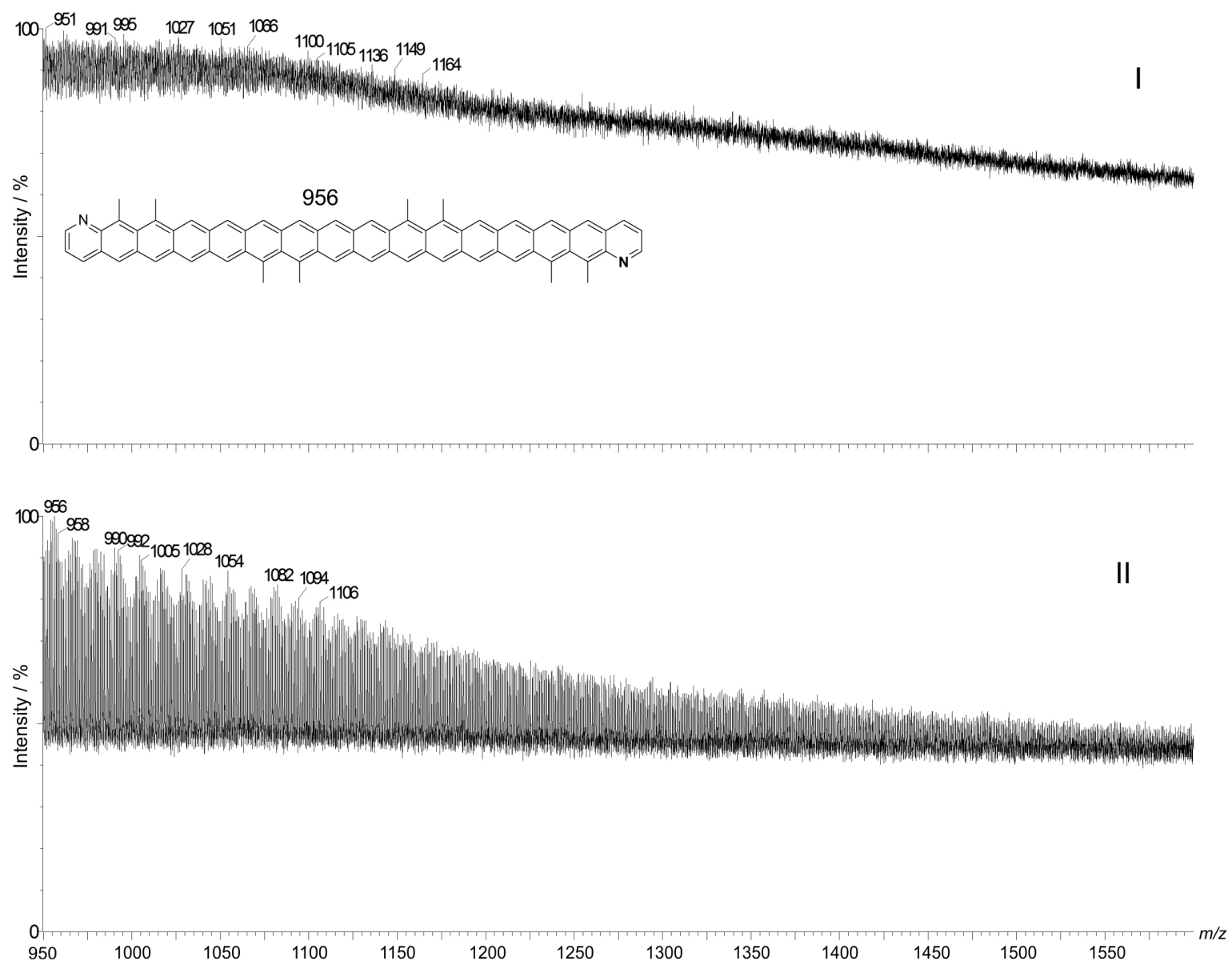

Figure 6. Mass spectrum of pitch I without matrix (I) and with matrix (II) at the region of $m / z, 950$ to 2000.

Another analytical method commonly used to monitor the growth of mesophase is solvent extraction. Literature reports a large number of solvents, such as heptane, toluene, tetrahydrofuran, pyridine, quinoline and $\mathrm{N}$-methyl-pyrrolidinone. However, the solvents behave differently according to the system and the content of the extracted material is not compatible. In addition to the low extraction of mesophase spheres in the initial stages of the heat treatment, these methods are time consuming with extraction and filtration steps..$^{1,49,50}$

The purpose of using low-field NMR was to present a new and fast methodology to accurately measure mesophase growth. Proton relaxation was used in these studies. The results obtained were compared with those from solvent extraction, using quinoline, N-methyl pyrrolidinone and toluene.

The spin-lattice is conventionally characterized by the relaxation time $\left(\mathrm{T}_{1}\right)$ which shows the return of a population of spins to the equilibrium of magnetization after a pulse of radio frequency. ${ }^{52-54}$ Evdokimov et al. ${ }^{55}$ studied the formation of asphaltene dispersions in petroleum/toluene through measurements of relaxation times of spin-spin $\left(\mathrm{T}_{2}\right)$, identifying monomers below $10 \mathrm{mg} \mathrm{L}^{-1}$, demonstrating the sensitivity of the method.

Table 1 shows the results from solvent extraction of some of the pitch samples.

Table 1. Characterization of samples by solvent extraction

\begin{tabular}{lccc}
\hline \multirow{3}{*}{ Samples } & \multicolumn{3}{c}{ Insoluble fraction / \% } \\
\cline { 2 - 4 } & $\begin{array}{c}\text { Toluene } \\
\text { (IT) }\end{array}$ & $\begin{array}{c}\text { Quinolein } \\
\text { (IQ) }\end{array}$ & $\begin{array}{c}\text { N-Methyl pirrolidone } \\
\text { (INMP) }\end{array}$ \\
\hline $\mathrm{A}$ & 8.8 & 0.1 & 0.9 \\
$\mathrm{C}$ & 24.9 & 3.8 & 8.7 \\
$\mathrm{E}$ & 28.0 & 7.0 & 13.5 \\
$\mathrm{G}$ & 37.1 & 16.2 & 24.1 \\
$\mathrm{I}$ & 57.1 & 45.1 & 49.8 \\
\hline
\end{tabular}

$\mathrm{T}_{1} \mathrm{H}$ relaxation data obtained at $300 \mathrm{~K}$ are presented in Table 2. The curve containing the equilibrium spins was mathematically fit using three exponentials. Mesophase regions were identified and quantified, thus shortening the analysis time and increasing the accuracy of the results when compared to the commonly used techniques (POM and extractions with solvents). 
Table 2. Relaxation times for proton spin-lattice of the studied samples, determined by low-field NMR using the program WINFIT

\begin{tabular}{|c|c|c|c|c|}
\hline Sample & $\begin{array}{c}\mathrm{T}_{1} \mathrm{H}^{\mathrm{a}} / \\
\mathrm{ms} \\
\end{array}$ & Intensity & $\begin{array}{l}\text { Proposed } \\
\text { dominium }\end{array}$ & $\begin{array}{c}\text { Mesophase / } \\
\%\end{array}$ \\
\hline \multirow{3}{*}{ A } & 52 & 8.69 & mesophasic & \multirow{3}{*}{2.1} \\
\hline & 1012 & 197.84 & aromatic & \\
\hline & 1105 & 207.68 & aromatic & \\
\hline \multirow{3}{*}{$\mathrm{C}$} & 430 & 107.69 & mesophasic & \multirow{3}{*}{26.6} \\
\hline & 1322 & 128.42 & aromatic & \\
\hline & 1957 & 127.33 & aromatic & \\
\hline \multirow{3}{*}{$\mathrm{E}$} & 41 & 20.61 & mesophasic & \multirow{3}{*}{52.3} \\
\hline & 788 & 147.66 & mesophasic & \\
\hline & 1808 & 153.50 & aromatic & \\
\hline \multirow{3}{*}{ G } & 61 & 61.70 & mesophasic & \multirow{3}{*}{56.9} \\
\hline & 746 & 181.46 & mesophasic & \\
\hline & 1215 & 184.46 & aromatic & \\
\hline \multirow{3}{*}{ I } & 103 & 110.84 & mesophasic & \multirow{3}{*}{64.1} \\
\hline & 531 & 141.21 & mesophasic & \\
\hline & 1303 & 141.13 & aromatic & \\
\hline \multirow{3}{*}{$\mathrm{J}$} & 0.3 & 11.12 & ------- & \multirow{3}{*}{5.4} \\
\hline & 60 & 26.55 & mesophasic & \\
\hline & 643 & 452.36 & aromatic & \\
\hline \multirow{3}{*}{$\mathrm{K}$} & 11 & 13.62 & ------- & \multirow{3}{*}{94.7} \\
\hline & 94 & 127.06 & mesophasic & \\
\hline & 212 & 116.73 & mesophasic & \\
\hline \multirow{3}{*}{ 2-Metilnaphtalene } & 1521 & 96.19 & aromatic & \multirow{3}{*}{------- } \\
\hline & 1745 & 95.46 & aromatic & \\
\hline & 1750 & 93.77 & aromatic & \\
\hline
\end{tabular}

aThese values are the $T_{1}$ results after adjustments with the three exponential curves.
$\mathrm{T}_{1}$ studies permitted us to observe two large areas: the aromatics and the mesophases. These results also showed that the heating time increases the mesophasic area. Taking the pitch $G$ and the sample of 2-methylnaphthalene as examples of aromatic and mesophasic areas, respectively, it can be suggested that polymerization, polycondensations and intermolecular rearrangements provoke an increase in the mesophasic area and a decrease in the aromatic area. This result is in agreement with the MALDI-TOF-MS data previously presented. The formation of the mesophase could be observed by adjusting the exponential distributions, graphically shown in Figure 7 with the amplitude of relaxation in time.

Jurkiewicz et al..$^{53}$ employed the technique of spinlattice relaxation of hydrogen to characterize coals. They suggested, preliminarily, that two phases (molecular and macromolecular) could be distinguished in the structure of coals. The longitudinal relaxation time $\left(\mathrm{T}_{1} \mathrm{H}\right)$ and data from insoluble fractions were correlated with the presence of mesophasic domains in different samples (Figure 8). The results of the determinations of insoluble fractions were lower than those obtained by ${ }^{1} \mathrm{H}$ NMR relaxometry, proving that they underestimated the formation of mesophase, especially in the early stages of the heat treatment. There is also a good correlation between low levels of insoluble
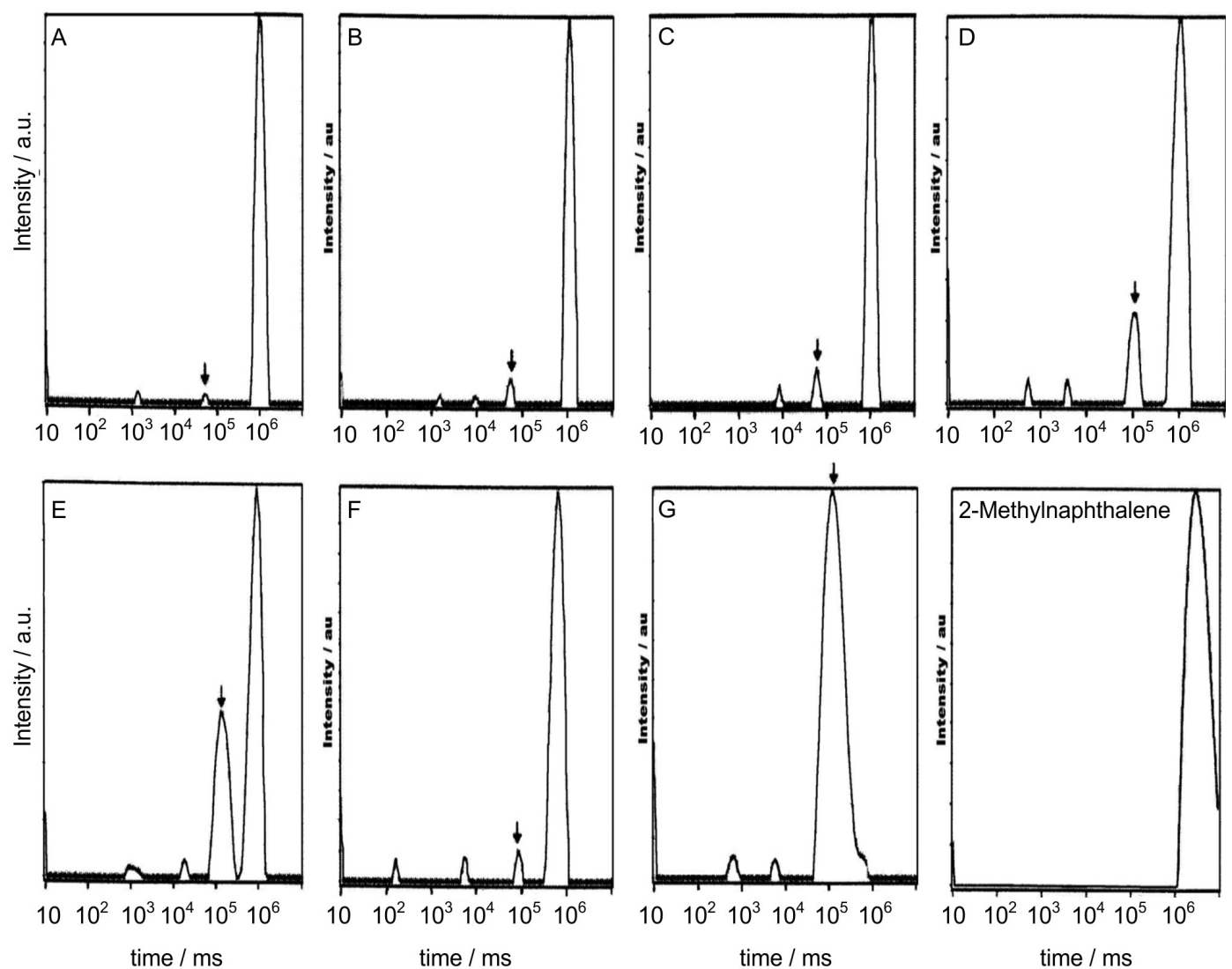

Figure 7. Relaxation amplitude versus spin-lattice relaxation times (D1=10 s, $300 \mathrm{~K})$ of the samples ( $\downarrow$ mesophase domain). 
fractions and NMR data. The results show the potential of the ${ }^{1} \mathrm{H}$ NMR relaxometry as a tool to characterize this type of system.

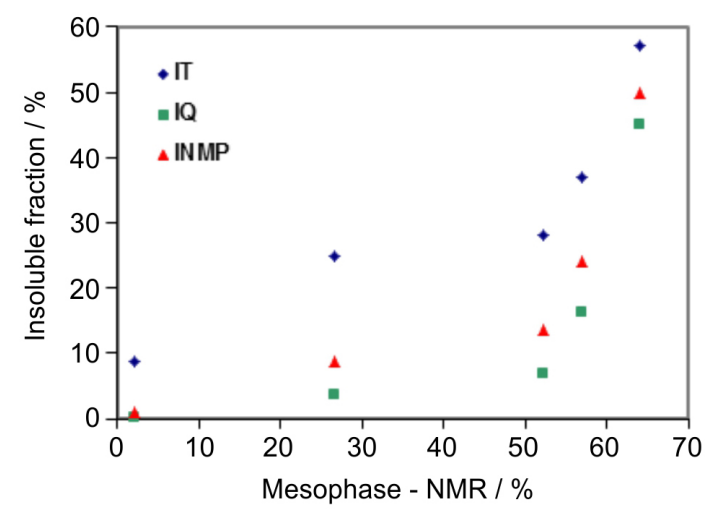

Figure 8. Correlation between the results $\mathrm{T}_{1} \mathrm{H}$ and the content of insoluble components in the pitch samples evaluated.

\section{NMR - high field}

The heat treatments applied in this study increased the levels of mesophase from 2.1 to $64.1 \%$ in samples A-I, respectively, making them insoluble in many organic solvents, heightening their softening point and making the employment of analytical techniques to study them unfeasible. NMR in solid state allowed the characterization of the mesophase in pitches, affording several structural parameters.

The spectra were obtained with cross polarization and magic angle spinning in order to increase the sensitivity and decrease the anisotropy of the chemical shift and the time of analysis. Because the pitches presented a low concentration of free radicals, it was possible to use cross-polarization with longer contact times $(5 \mathrm{~ms})$, as recommended by Andrésen et al. ${ }^{3}$ Figure 9 shows the spectra obtained to the pitch $\mathrm{C}$ with cross polarization, magic angle spinning (CP MAS), single pulse and magic angle spinning (SPE MAS). It is noticeable that there is an overlap between the normalized spectra, confirming the shifts and intensities and showing that the crosspolarization with a contact time of $5 \mathrm{~ms}$ did not cause discrepancies in the results. It is clear, however, that the standard TKS was not favored by the increased sensitivity in the CP MAS spectrum because of the mobility of its methyl groups. The spectrum of a single pulse shows, by obtaining the side band at $60 \mathrm{ppm}$, that there are at least three distinct regions of aromatic carbons.

Figure 10 shows a typical spectrum (sample A) obtained for our pitch samples. Several regions can be identified by the chemical shifts: the standard TKS at $3.5 \mathrm{ppm}$, the methyl region between 5-25 ppm, the methylene region between 25-45 ppm and the aromatic region between 100-150 ppm.

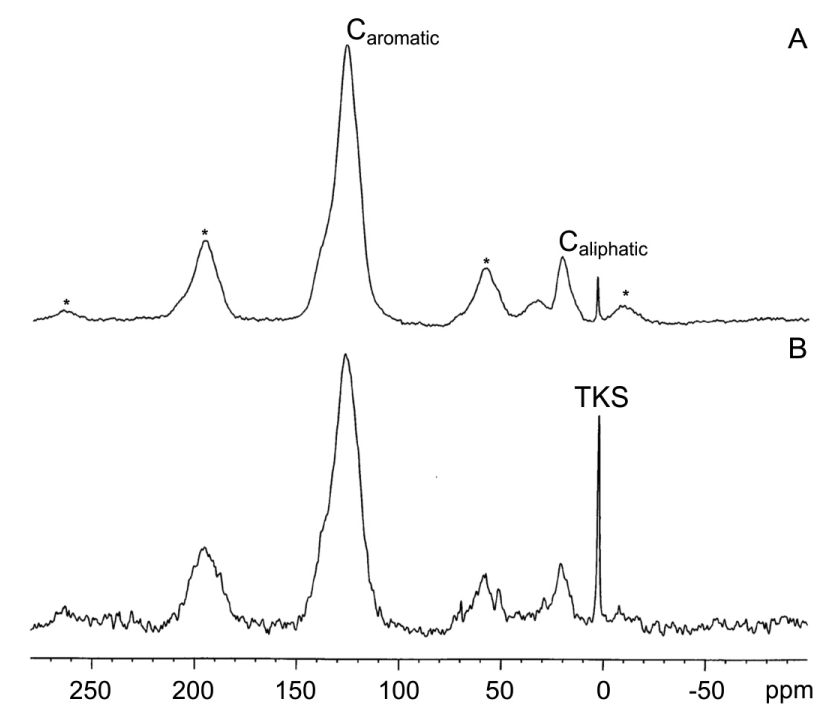

Figure 9. NMR spectra of sample C: (A) CP MAS and (B) SPE MAS; * indicates lateral bands.

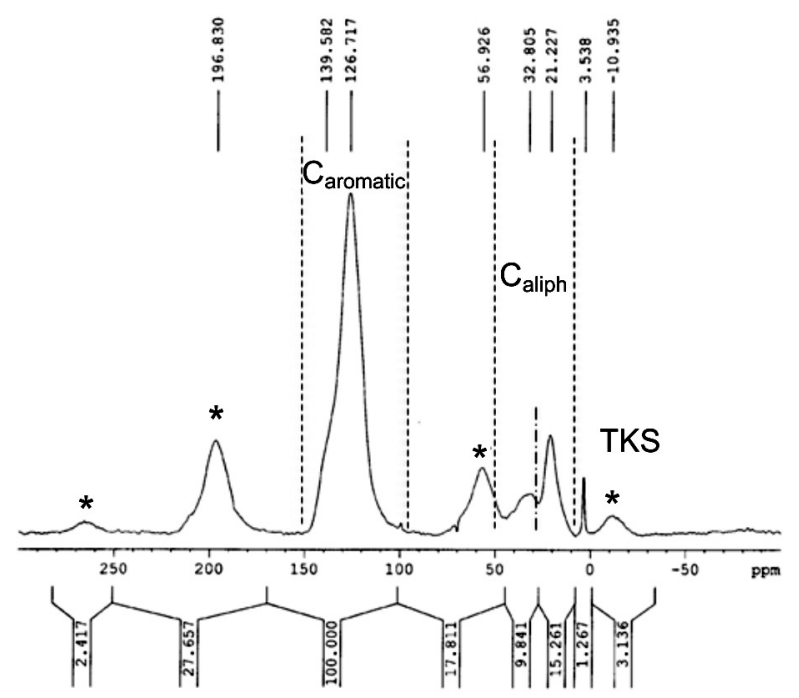

Figure 10. ${ }^{13} \mathrm{C}$ NMR-CP MAS spectrum of sample A (time of contact: $5 \mathrm{~ms})$.

The two peaks at 126 and $139 \mathrm{ppm}$, can be identified as possible quaternary aromatic carbons.

Table 3 and Figure 11 show a decrease in the concentration of aliphatic carbons with heating time for samples A-I, respectively. This phenomenon is probably due to the polymerization and polycondensation reactions and rearrangements and formation of mesogens, increasing the aromaticity of the pitches and volatilizing the lighter compounds.

The reduction in methyl content with heating probably occurs because they are consumed in the radical based polycondensation. On the other hand, the methylene content in samples E, G, I and K remained approximately constant. These methylenes could 
Table 3. Content of aromatic and aliphatic carbons in the pitches samples

\begin{tabular}{lcccc}
\hline \multirow{2}{*}{ Sample } & \multirow{2}{*}{$\begin{array}{c}\text { Aromatic } \\
\text { carbons / \% }\end{array}$} & \multicolumn{3}{c}{ Aliphatic carbons / \% } \\
\cline { 3 - 5 } & 85.1 & 8.6 & 5.5 & 14.1 \\
\hline A & 88.5 & 6.7 & 5.5 & 12.2 \\
C & 90.4 & 6.4 & 2.9 & 9.3 \\
E & 92.2 & 5.2 & 2.2 & 7.4 \\
G & 91.7 & 4.1 & 3.0 & 7.1 \\
I & 94.7 & 2.6 & 2.7 & 5.3 \\
K & & & &
\end{tabular}

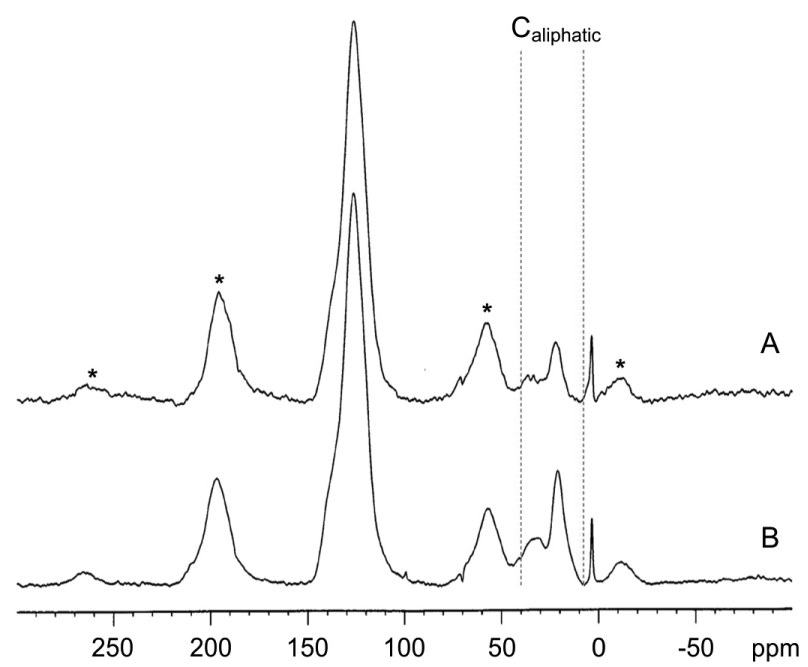

Figure 11. ${ }^{13} \mathrm{C}$ NMR-CP MAS spectra with the aromatic regions normalized of: pitch I (A) and pitch A (B).

possibly participate in structures, such as fluorenes or naphthenic groups. The content of non-protonated carbons were obtained by gap dipole (GD) at different contact times. In these experiments, the rate of dephasing of the ${ }^{13} \mathrm{C}$ signal is related to the magnitude of dipolar interactions, which depend on geometric factors, namely the ${ }^{1} \mathrm{H}-{ }^{13} \mathrm{C}$ internuclear distance and the angle between the internuclear and magnetic field vectors. It can be concluded that in small times of GD, there is a mixture of signals from protonated and not protonated carbons, while for spectra with longer contact times, the signs observed are composed of carbon atoms weakly bonded with hydrogen or not protonated. Figure 12 shows the typical spectra obtained by the dipole phase shift.

The signal intensities of aromatic carbons rapidly decrease until $60 \mu$ s, becoming almost constant at higher times. Equation 1 was adjusted to this data set. Extrapolation of equation 1 allows us to determine the level of non-protonated aromatic carbons present in the samples $\left[\mathrm{I}_{\mathrm{Lor}}(0)\right]$. Figure 13 shows the fitting of equation 1 to the experimental data of sample A.

$I\left(t_{D D}\right)=I_{\text {Gauss }}(0) \exp \left(-t_{D D}^{2} / 2 T_{2, \text { Gauss }}^{2}\right)+I_{\text {Lor }}(0) \exp \left(-t_{D D} / T_{2, \text { Lor }}\right)$

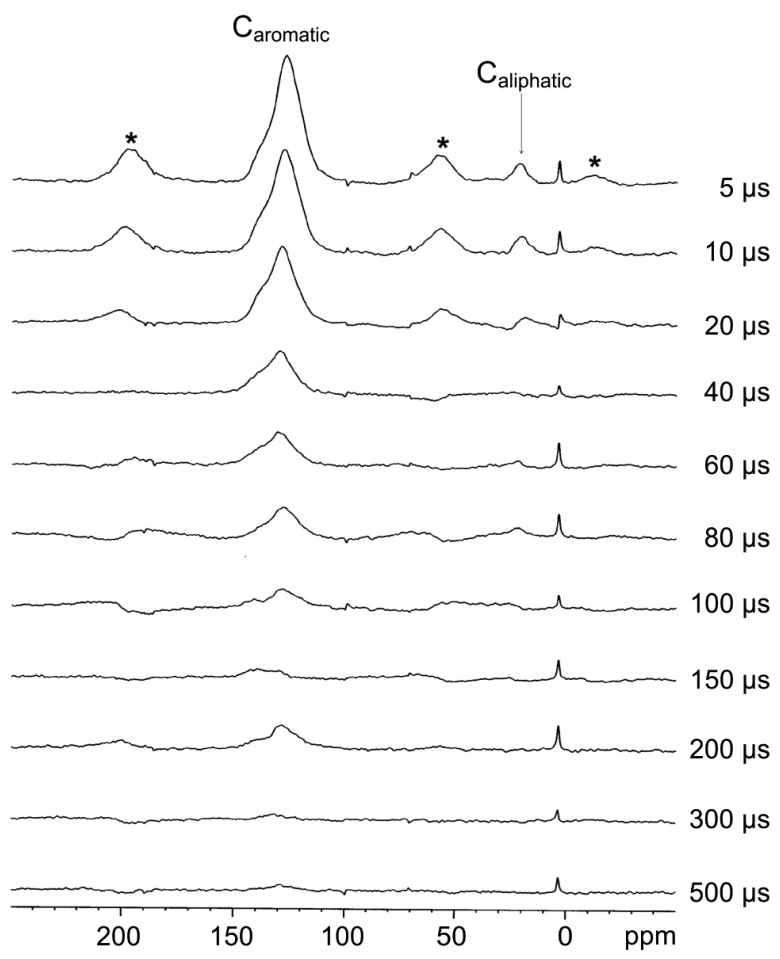

Figure 12. Typical spectra of the dipolar gap of sample I.

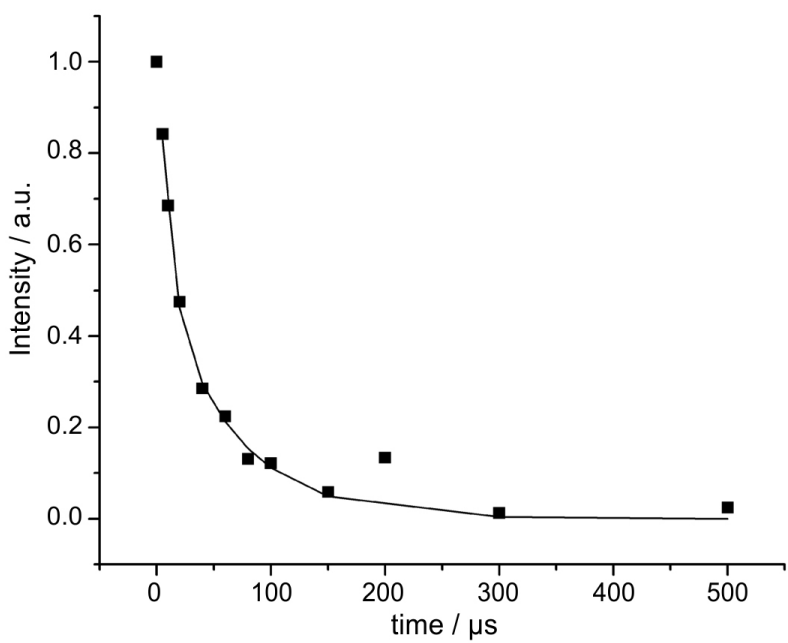

Figure 13. Plot of the fitting of equation 1 to the experimental data of sample A.

Results for the parameters $\mathrm{I}_{\text {Gauss }}(0)$ and $\mathrm{I}_{\text {Lor }}(0)$ after the fitting with experimental data are listed in Table 4.

The concentrations of quaternary carbons are represented by the values of $\mathrm{I}_{\mathrm{Lor}}(0)$, consistent with the results obtained by Andrésen et al. ${ }^{3}$ It can be observed that there is an initial increase with further stabilization (samples E, G and I). This result demonstrates that the polycondensation reactions probably occur at an early stage of heat treatment when there is a greater mobility. After this stage, only spatial adjustments and mesophasic formation occurs. 
Table 4. Parameters fitted to the signals intensity in the aromatic region after dipole phase shift

\begin{tabular}{lcc}
\hline Sample & $\mathrm{I}_{\text {Gauss }}(0)$ & $\mathrm{I}_{\text {Lor }}(0)$ \\
\hline A & 0.56 & 0.35 \\
C & 0.37 & 0.51 \\
E & 0.27 & 0.64 \\
G & 0.41 & 0.59 \\
I & 0.32 & 0.60 \\
\hline
\end{tabular}

\section{Electronic paramagnetic resonance (EPR)}

Results of the EPR are listed in Table 5, where can be seen that the increase in the heating time of the pitches (samples C-H) provoked a higher concentration of unpaired spins.

Table 5. Concentration of spins in the pitches samples

\begin{tabular}{lccc}
\hline Sample & Amplitude / cm & $\begin{array}{c}\text { Relative } \\
\text { amplitude }\end{array}$ & $\begin{array}{c}\text { Concentration / } \\
\left(\times 10^{17} \text { spins g }^{-1}\right)\end{array}$ \\
\hline $\mathrm{C}$ & 2.8 & 0.25 & 0.63 \\
$\mathrm{D}$ & 3.5 & 0.32 & 0.80 \\
$\mathrm{E}$ & 5.5 & 0.50 & 1.25 \\
$\mathrm{~F}$ & 7.9 & 0.72 & 1.80 \\
$\mathrm{G}$ & 5.8 & 0.53 & 1.33 \\
$\mathrm{H}$ & 11.0 & 1.00 & 2.50 \\
$\mathrm{~J}$ & 8.2 & 0.75 & 1.88 \\
$\mathrm{~K}$ & 5.6 & 0.51 & 1.30 \\
\hline
\end{tabular}

Kershaw et al. ${ }^{56}$ studying the formation of mesophases, showed an increased concentration of free radicals during the thermal treatment of petroleum pitches, suggesting that during the carbonization, the concentration of stable free radicals would be directly correlated to the molecular weight. By correlating the formation of the mesophase with the spin concentration, they concluded that the growth of the molecules precedes the mesophase formation because high concentrations of unpaired spins were observed in samples of low mesophase content and with high molecular weight. This conclusion is in agreement with data in Table 5 and with the content of quaternary carbons obtained by ${ }^{13} \mathrm{C}$ NMR-CPMAS with dipolar phase shift.

The concentration of $1.88 \times 1017$ spins g ${ }^{-1}$ obtained for the superior part of the centrifuged pitch (sample $J$ ) is bigger than expected for an anisotropic phase, suggesting the presence of high molecular weight molecules. ${ }^{57,58}$ The concentration obtained for the inferior part of the centrifuged pitch (sample $\mathrm{K}$ ) is smaller than the superior (sample J). This result is in agreement with the work by
Kershaw et al. ${ }^{56}$ that show an increase in spin concentration with growing molecular weight, characterizing the phase before the formation of mesophase. The results of microscopy and magnetic resonance imaging showed a low level of regions in the mesophase pitch $(2.1 \%)$ (sample J) and a large region in the anisotropic pitch (94.7\%) (sample K).

Andrésen $e t a l .{ }^{3}$ studied heat-treated tar pitches and reported the presence of unpaired electrons in the range of 0.2 to $6.3 \times 10^{19}$ spin $\mathrm{g}^{-1}$. They concluded that the detection of ${ }^{13} \mathrm{C}$ by NMR was not affected because these levels are considered low for coals and pitches. The concentration of spins in the samples remained two orders of magnitude below that found by Andrésen $e t a l .^{3}$

\section{Optic microscopy}

An important assay in the characterization of mesophases is the polarized light optical microscopy, using accessories that accentuate the contrast inherent to the interference figures (like filters of $\lambda / 2$ and $\lambda$ ). Although this type of microscope did not reach molecular resolution and was unable to investigate the mesophases during nucleation, it provides figures of interference that result in a good polychromatic contrast between what is initially the pitch matrix and the mesophase in the several stages of growth. Therefore, it represents a tool for identification and quantification of the anisotropic phase and allows the identification of shape, size and orientation of the crystalline structures. These textures are classified according to the size of particles or aggregates: mosaics $(<10 \mu \mathrm{m})$, domains $(<60 \mu \mathrm{m}$ in length and $<5 \mu \mathrm{m}$ diameter) and large areas ( $>60 \mu \mathrm{m}$ in length and $>10 \mu$ m diameter). ${ }^{59}$

The micrographs obtained for samples B-J are shown in Figures 14-16 and show the mesophases growing by thermal treatment. In the initial stage, the mesophases present a spherical profile, which shows that the energies of the interfaces allow a position of minimal surface energy. ${ }^{1}$

Sample B, heated to $430^{\circ} \mathrm{C}$ for $30 \mathrm{~min}$, showed small, isolated mesophase spheres detected by a 100 fold increase (Figure 16), which is technically impossible to quantify by microscopy. Low field NMR, however, was able to quantify the mesophases ( $2.1 \%$ in the starting pitch (sample A)) as can be seen in Table 3 and Figure 11.

The micrographs of samples C-F show the increasing growth of the spheres through the mechanisms of polymerization, polycondensation and coalescence of mesogenic presents from isolated spheres to aggregates. The borders between the phases were very well delineated. In samples G-I, there was the formation of anisotropic 

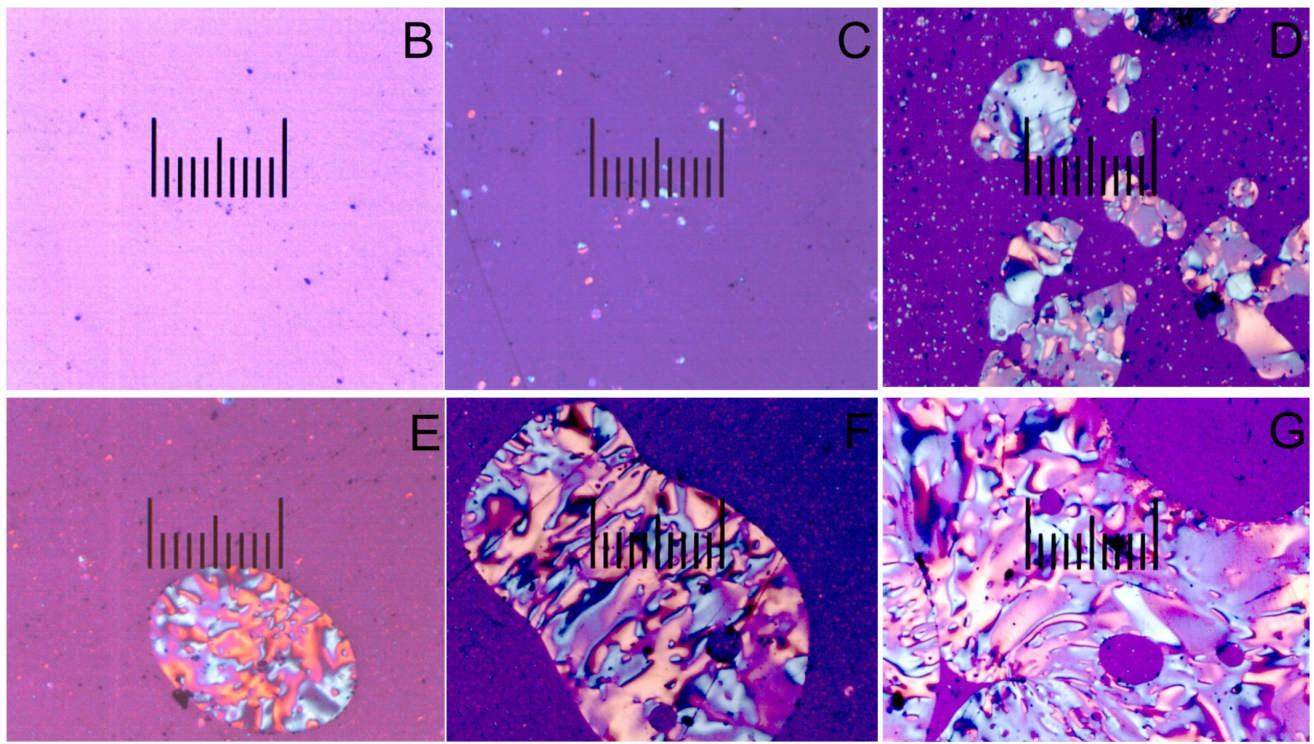

Figure 14. Micrographs of polarized light of the pitches submitted to the thermic treatment (samples B-G) augmented 50 times. Scale of $200 \mu \mathrm{m}$.

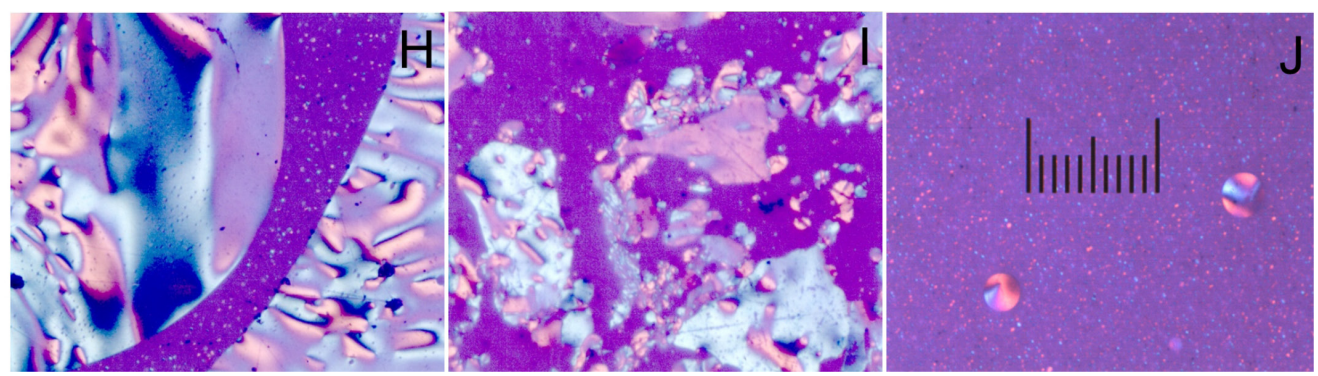

Figure 15. Micrographs of polarized light of the pitches submitted to the thermic treatment (H and I) and to centrifugation (superior part - sample J), augmented 50 times. Scale of $200 \mu \mathrm{m}$.

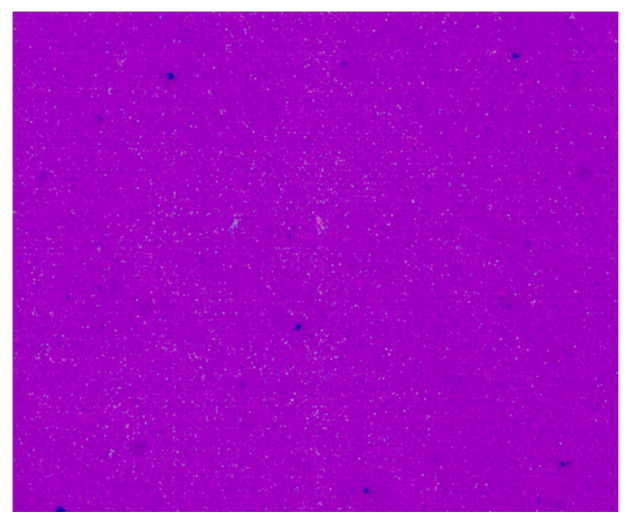

Figure 16. Micrographs of polarized light of the sample B augmented 100 times. Scale of $200 \mu \mathrm{m}$.

domains. The difference in the deformability of the phases indicates that the viscosity of the mesophase is appreciably higher than in the isotropic, resulting in the encapsulation of the matrix at the anisotropic regions already observed by Kershaw et al. ${ }^{56}$

Sample J, the superior part of the centrifuged pitch, presented mesophasic spheres dispersed in the isotropic matrix, showing that the centrifuge separation was not absolute, in accordance with NMR data from Table 3 and Figure 11 presenting a value of $5.4 \%$ for the anisotropic region.

The studied system shows the formation of anisotropic domains involving small isotropic regions. This process of coalescence of mesophase spheres probably occurred with a slow increase in viscosity, which facilitates the movements and associations of mesogenic macromolecules. ${ }^{48}$

The mesophasic domains shown in samples $\mathrm{H}$ and I present signs of a large mechanic deformation, with the isotropic phase present in spheres or isolation of extended anisotropic regions. The presence of domains and small spheres of mesophase in the micrograph of sample I demonstrates that the process of coalescence and growth had not yet been completed. This result was confirmed by quantitative data from low-field NMR pointing to the value of $64.1 \%$ of mesophase and showing that heating was interrupted before the achievement of $100 \%$ of anisotropic pitch. Petroleum pitches, containing both isotropic and anisotropic parts, are difficult to be extruded into carbon fibers because there is a large difference in viscosity and density between the two fractions. The size and content of 
the mesophase can be controlled by temperature and time of heat treatment. ${ }^{50}$

\section{TGA}

The pitches, when subjected to thermal treatment, undergo several physical and chemical changes resulting in an infusible polymer, known as coke. During this conversion an intermediate liquid crystal forms, which is the mesophase, and the final properties of the product are controlled by the nature of the precursor and the mechanism of its transformation into coke. The physical stability and the thermic reactivity of the polynuclear aromatic molecules that constitute the pitch are correlated to the sizes of the molecules, their structures and functionalities. ${ }^{60}$

Different physical and chemical phenomena occur during pyrolysis of pitches between 200 and $800{ }^{\circ} \mathrm{C}$ : devolatilization, polymerizations, polycondensations, cracking reactions and molecular rearrangements. The reduction of the molecular weight normally starts close to $250{ }^{\circ} \mathrm{C}$ and achieves its maximum between 350 and $450{ }^{\circ} \mathrm{C}$. This reduction is mainly attributed to the physical removal of volatile species of low molecular weight. The evolution of gas is significant near $400{ }^{\circ} \mathrm{C}$, consisting mainly of $\mathrm{H}_{2}$ and $\mathrm{CH}_{4}$, but also includes other lighter hydrocarbons generated in chemical reactions. From 460 to $560{ }^{\circ} \mathrm{C}$, exothermic reactions corresponding to the polymerization and polycondensations occur. The endothermic behavior is pronounced after $560{ }^{\circ} \mathrm{C}$ and has its maximum near $740{ }^{\circ} \mathrm{C}$, with the aromatization and starting of the transformation of semi-coke into coke. Between 480 and $500{ }^{\circ} \mathrm{C}$, there is an increased emission of light alkanes (C1-C4). After $750{ }^{\circ} \mathrm{C}$, hydrogen is detected. ${ }^{27,60}$ The ordering of the aromatic compounds present in a heat treated pitch leads to the formation of mesophases, which is controlled by the average size of molecules and their molecular distribution. In the process of carbonization, the dehydrogenation and growing of the size of the aromatic molecules occurs together with the production of stable free radicals. ${ }^{60}$ The mass loss of pitches A-H and $\mathrm{J}$ analyzed by TGA can be subdivided into three distinct regions, as shown in Table 6.

The behavior of the pitches studied (A-H) agrees with the literature data. ${ }^{27,60}$ The first region $\left(250-450{ }^{\circ} \mathrm{C}\right)$ can be identified through the volatilization of the lighter molecules, the second region $\left(460-570{ }^{\circ} \mathrm{C}\right)$ can be attributed to the mesogenic molecules with a degree of polymerization and planar spatial $\pi-\pi$ arrangement, and the third region $\left(>560{ }^{\circ} \mathrm{C}\right.$ ) is related to aromatization and loss of hydrogen with formation of semi-cokes and cokes. For sample $\mathbf{J}$ that is obtained from the top of a centrifuged pitch, it is also seen the presence of three regions. Data from optical microscopy and low-field NMR show that the presence of small mesogenic of high molecular weight, dissolved in an isotropic pitch, took to a better definition of $\mathrm{T}_{\max }$ between the first and second regions, showing a more homogeneous distribution of phases. It is also possible to observe that pitches E-J presented a higher mesogenic concentration demonstrating a more intense stage of polymerization of the aromatic rings.

Figure 17 shows the curve of weight loss and its derivative, obtained for sample $\mathrm{K}$. It is observed that there are small losses of mass in the first $(7.3 \%)$ and second $(4.3 \%)$ regions. Considering that $(i)$ the first region is composed of lighter molecules, with no intermolecular interactions, like $\pi-\pi$; (ii) this sample was subjected to drastic temperature and mechanical forces; (iii) these forces cause the disruption of possible isotropic regions encapsulated by the anisotropic ones, forming two pure phases (being the largest mesophasic and the smallest

Table 6. Results of the thermic analysis of pitches A-H and J-K

\begin{tabular}{|c|c|c|c|c|c|c|c|c|c|c|c|c|}
\hline \multirow{2}{*}{ Sample } & \multicolumn{4}{|c|}{$1^{\text {st }}$ region } & \multicolumn{4}{|c|}{$2^{\text {nd }}$ region } & \multicolumn{4}{|c|}{$3^{\text {rd }}$ region } \\
\hline & $\mathrm{T}_{\mathrm{i}} /{ }^{\circ} \mathrm{C}$ & $\mathrm{T}_{\mathrm{f}} /{ }^{\circ} \mathrm{C}$ & $\mathrm{T}_{\max } /{ }^{\circ} \mathrm{C}$ & $\%$ & $\mathrm{~T}_{\mathrm{i}} /{ }^{\circ} \mathrm{C}$ & $\mathrm{T}_{\mathrm{f}} /{ }^{\circ} \mathrm{C}$ & $\mathrm{T}_{\max } /{ }^{\circ} \mathrm{C}$ & $\%$ & $\mathrm{~T}_{\mathrm{i}} /{ }^{\circ} \mathrm{C}$ & $\mathrm{T}_{\mathrm{f}} /{ }^{\circ} \mathrm{C}$ & $\mathrm{T}_{\max } /{ }^{\circ} \mathrm{C}$ & $\%$ \\
\hline A & 33 & 443 & 340 & 43.7 & 443 & 550 & 545 & 6.4 & 550 & 900 & 685 & 51.7 \\
\hline B & 33 & 460 & 336 & 45.7 & 460 & 540 & 533 & 4.2 & 540 & 900 & 704 & 47.3 \\
\hline $\mathrm{C}$ & 33 & 512 & 409 & 45.8 & 512 & 604 & 530 & 4.2 & 604 & 900 & 852 & 41.1 \\
\hline $\mathrm{D}$ & 33 & 472 & 355 & 35.8 & 472 & 594 & 550 & 4.7 & 594 & 900 & 803 & 56.7 \\
\hline $\mathrm{E}$ & 33 & 477 & 414 & 31.4 & 477 & 600 & $492 / 523$ & 10.3 & 600 & 900 & 865 & 50.0 \\
\hline $\mathrm{F}$ & 33 & 487 & $363 / 433$ & 23.6 & 487 & 598 & 553 & 6.8 & 598 & 900 & 856 & 67.6 \\
\hline G & 33 & 474 & 372 & 21.1 & 474 & 606 & 554 & 7.2 & 606 & 900 & 840 & 69.6 \\
\hline $\mathrm{H}$ & 33 & 486 & $387 / 447$ & 19.1 & 486 & 616 & 540 & 7.9 & 616 & 900 & 900 & 43.4 \\
\hline $\mathrm{J}$ & 33 & 490 & 446 & 17.3 & 490 & 612 & 543 & 12.4 & 612 & 900 & 900 & 43.3 \\
\hline $\mathrm{K}$ & 33 & 440 & 329 & 7.3 & 440 & 555 & 484 & 4.3 & 555 & 900 & 900 & 69.9 \\
\hline
\end{tabular}


isotropic), it can be concluded, based on the TGA analysis, that there is approximately $93.7 \%$ of mesophase. This result agrees with the analysis of low-field NMR that pointed to a mesophase content of $94.7 \%$.

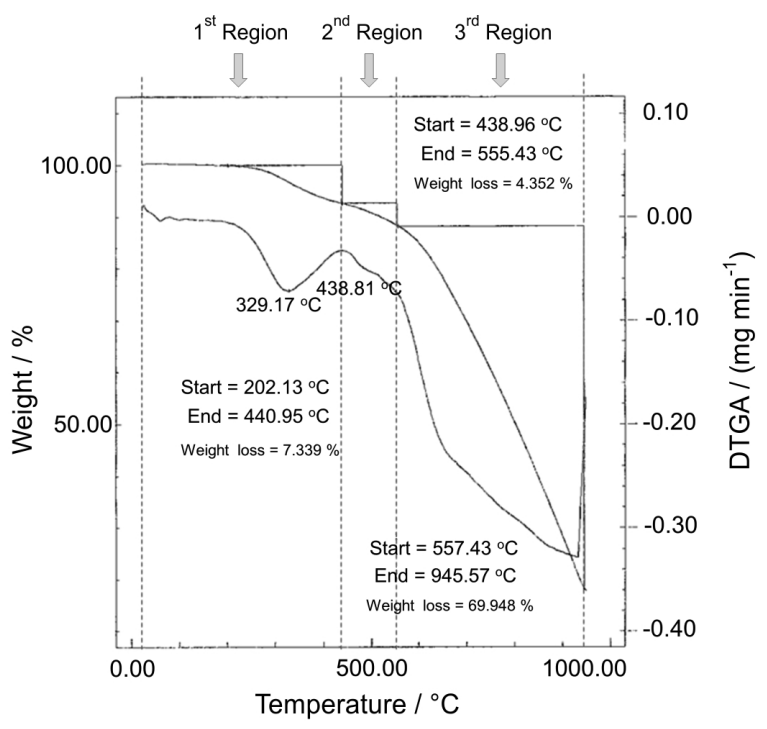

Figure 17. Thermogravimetric analysis (TGA and DTGA) of sample K.

\section{Conclusions}

The first technique for solid analysis employed in the petroleum pitch samples (B-I) (MALDI-TOF-MS) allowed us to monitor the structural changes of pitches by thermal treatment, making them insoluble or partially soluble in many organic solvents and increasing their softening points. The two methodologies used, with and without matrix, were efficient and presented similar results. In the experiment with the TCNQ matrix, signals of the heavier compounds were intensified when compared to the experiment without matrix. The same compounds were found in both experiments, and no coalescence of the molecules was observed. Spectra were divided into four regions, according to the oligomeric nature presented: monomeric $(\mathrm{m} / z, 200$ to $400)$, dimeric $(\mathrm{m} / \mathrm{z}, 400$ to 650$)$, trimeric $(\mathrm{m} / \mathrm{z}, 650$ to 950$)$ and tetrameric ( $\mathrm{m} / \mathrm{z} 950$ to 1600$)$. Signs of the compounds with higher molecular weights increased with the time of heat treatment. It was also observed that the most intense signs among the molecular ions present probably belong to compounds containing heteroatoms such as nitrogen. The results showed that from the aromatic residue up to pitch sample I, the molecules underwent polymerization, polycondensation and classical free radical reactions, in agreement with the literature. MALDI-TOF-MS showed the distribution of molecular weights in the pitch, an essential factor for the production of carbon fibers, among other advanced composite of carbon.
The use of the relaxation of hydrogen in the solid phase allowed us to track and quantify the formation of mesophases, a result that we believe is new in the literature. In comparison with traditional techniques, insoluble fractions in organic solvents and polarized light optical microscopy showed that it is possible to obtain, by relaxation, more accurate results at an early stage of formation of mesophases, without the need for sample preparation and with a reduction in the time of analysis.

The use of techniques for high-power decoupling, magic angle spinning, cross polarization and dipolar gap, allowed the use of ${ }^{13} \mathrm{C}$ NMR, with high-resolution spectra in solid form, in all samples. Through direct and non-destructive measurements, it was obtained the content of aromatic and aliphatic carbons, as well as the degree of protonation of these carbons. It was observed that there was an initial increase in levels of quaternary carbons in the samples and a subsequent stabilization, in agreement with the literature data suggesting that the reactions of polymerization and polycondensation happen in the first step and the spatial arrangements for the formation of mesophase happen in the last step.

Results from EPR showed an increase in the concentration of unpaired spins with the thermal treatment, suggesting the occurrence of free radicals reactions. A higher amount of unpaired spins was observed at the top of the centrifuged pitch (sample J) than in the bottom (sample K). This could be explained by the presence of reactive molecules with great mobility at the top. The concentration of paramagnetic centers in the different samples were two orders of magnitude smaller than those observed in the literature for coals and pitches, an indicative factor of the excellent quality of these carbon materials.

Optical microscopy with polarized light was an important tool in visualizing the consequences of heat treatment on the formation of mesophases, showing the interfaces between the anisotropic and isotropic regions as well as the process of coalescence of mesophase.

The study of the thermic transformations undergone by the different samples (A-K) was followed by thermo gravimetric analysis. The curves of weight loss and its derivatives revealed three distinct regions in the samples. The first one is characterized by the volatilization of lighter and not mesogenic molecules, the second is attributed to small mesogenic molecules and the third one composed of molecules with higher molecular weights and $\pi-\pi$ intermolecular interactions on the mesophase.

\section{Acknowledgments}

The Authors wish to thank the Brazilian financial agencies CNPq, FAPERJ and CAPES for financial support 
and the Federal University of Rio de Janeiro (UFRJ) and the Military Institute of Engineering (IME) for the physical infrastructure and working space.

\section{References}

1. March, H.; Martínez-Escandell, M.; Rodríguez-Reinoso, F.; Carbon 1999, 37, 363.

2. Morgan, P.; Carbon Fibers and Their Composites, $1^{\text {st }}$ ed.; Taylor \& Francis: Boca Raton, 2006.

3. Andrésen, J. M.; Martín, Y.; Moinelo, S. R.; Maroto-Valer, M. M.; Snape, C. E.; Carbon 1998, 36, 1043.

4. Hurt, R. H.; Hu, Y.; Carbon 1999, 37, 281.

5. Brooks, J. D.; Taylor, G. H. In Chemistry and Physics of Carbon, vol. 4; Walker Jr., P. L., ed.; Marcel Dekker: New York, 1968.

6. Mochida, I.; Fujimoto, K.; Oyama, T. In Chemistry and Physics of Carbon, vol 24; Walker Jr., P. L., ed.; Marcel Dekker: New York, 1968.

7. Harada, Y.; Matsunaga, Y.; Miyajima, N.; Sakamoto, S. J.; J. Mater. Chem. 1995, 5, 2305.

8. Mochida, I.; Fujiura, R.; Kojima, T.; Sakamoto, H.; Yoshimura, T.; Carbon 1995, 33, 265.

9. Fujiura, R.; Kojima, T.; Komatsu, M.; Mochida, I.; Carbon 1995, 33, 1061.

10. Marsh, H.; Gerus-Piasecka, I.; Grint, A.; Fuel 1980, 59, 343.

11. Marsh, H.; Mochida, I.; Scott, E.; Sherlock, J.; Fuel 1980, 59 , 517.

12. Grint, A.; Marsh, H.; Fuel 1981, 60, 513.

13. Grint, A.; Marsh, H.; Fuel 1981, 60, 519.

14. Ragan, S.; Marsh, H.; Fuel 1981, 60, 522.

15. Weinberg, V. A.; White, J. L.; Yen, T. F.; Fuel 1983, 62, 1503.

16. Lewis, I. C.; Fuel 1987, 66, 1527.

17. Hutchenson, K. W.; Roebers, J. R.; Thies, M. C.; J. Supercrit. Fluids 1991, 4, 7.

18. Hutchenson, K. W.; Roebers, J. R.; Thies, M. C.; Carbon 1991, $29,215$.

19. Kershaw, J. R.; Black, K. J. T.; Energy Fuels 1993, 7, 420.

20. Menéndez, R.; Granda, M.; Bermejo, J.; Marsh, H.; Fuel 1994, $73,25$.

21. Cohen, C. S.; Stansberry, P. G.; Stiller, A. H.; Hobbs, G.; Vavro, K.; Miller, M. R.; Energy Fuels 1995, 9, 1051.

22. Fujiura, R.; Kojima, T.; Komatsu, M.; Mochida, I.; Carbon 1995, 33, 1061.

23. Song, H.; Liu, L.; Qian, S.; Zhang, B.; Fuel 1996, 75, 1331.

24. Bermejo, J.; Granda, M.; Menéndez, R.; García, R.; Tascón, J. M. D.; Fuel 1997, 76, 179.

25. Dauché, F. M.; Bolaños, G.; Blasig, A.; Thies, M. C.; Carbon 1998, 36, 953.

26. Zhuang, M. S.; Thies, M. C.; Energy Fuels 2000, 14, 70.
27. Dumont, M.; Chollon, G.; Dourges, M. A.; Pailler, R.; Bourrat, X.; Naslain, R. Bruneel, L.; Couzi, M.; Carbon 2002, 40, 1475.

28. Méndez, A.; Santamaría, R.; Granda, M.; Menéndez, R.; Energy Fuels 2004, 18, 22.

29. Álvarez, P.; Sutil, J.; Santamaria, R.; Blanco, C.; Menéndez, R.; Granda, M.; Energy Fuels 2008, 22, 4146.

30. Cristadoro, A.; Kulkarni, S. U.; Burgess, W. A.; Cervo, E. G.; Räder, H. J.; Müllen, K.; Bruce, D. A.; Thies, M. C.; Carbon 2009, 47, 2358.

31. Burgess, W. A.; Pittman, J. J.; Marcus, R. K.; Thies, M. C.; Energy Fuels 2010, 24, 4301.

32. Burgess, W. A.; Thies, M. C.; Carbon 2011, 49, 636.

33. Edwards, W. F.; Jin, L.; Thies, M. C.; Carbon 2003, 41, 2761.

34. Cato, A. D.; Edie, D. D.; Carbon 2003, 41, 1411.

35. Kim, C. J.; Ryu, S. K.; Rhee, B. S.; Carbon 1993, 31, 833.

36. Skelton, R.; Dubois, F.; Zenobi, R.; Anal. Chem. 2000, 72, 1707.

37. Przybilla, L.; Brand, J. D.; Yoshimura, K.; Rader, H. J.; Mullen, K.; Anal. Chem. 2000, 72, 4591.

38. Edwards, W. F.; Thies, M. C.; Fluid Phase Equilib. 2004, 224 , 231.

39. Edwards, W. F.; Thies, M. C.; Fluid Phase Equilib. 2005, 228, 421.

40. Hanton, D. S.; Parees, D. M.; J. Am. Soc. Mass Spectrom. 2005, 16, 90.

41. Edwards, W. F.; Thies, M. C.; Carbon 2006, 44, 243.

42. Lima, A. L. S.; Pinto, A. C.; San Gil, R. A. S.; Tavares, M. I. B.; J. Braz. Chem. Soc. 2007, 18, 255.

43. Torregrosa-Rodriguez, P.; Martínez-Escandell, M.; Rodriguez-Reinoso, F.; Marsh, H.; Salazar, C. G.; Pazón, E. R.; Carbon 2000, 38, 535.

44. Johnson, B. R.; Bartle, K. D.; Domin, M.; Herod, A. A.; Kandiyoti, R.; Fuel 1998, 77, 933.

45. Marzec, A.; Fuel Process. Technol. 2002, 77-78, 25.

46. Artok, L.; Su, Y.; Hirose, Y.; Hosokawa, M.; Murata, S.; Nomura, M.; Energy Fuels 1999, 13, 287.

47. Suelves, I.; Islas, C. A.; Herod, A. A.; Kandiyoti, R.; Energy Fuels 2001, 15, 429.

48. Mochida, I.; Yoon, S. H.; Qiao, W.; J. Braz. Chem. Soc. 2006, 17, 1059.

49. Bunsell, R. A.; Fiber Reinforcements for Composite Materials, $1^{\text {st }}$ ed.; Elsevier: Amsterdam, 1988.

50. Mochida, I.; Korai, Y.; Ku, C.; Watanabe, F.; Sakai, Y.; Carbon 2000, 38, 305.

51. Li, T. Q.; Wang, C. Y.; Zhang, J. M.; Carbon 2002, 40, 2037.

52. Cutmore, N. G.; Sowerby, B. D.; Lynch, L. J.; Webster, D. S.; Fuel 1986, 65, 34.

53. Jurkiewicz, A.; Idziak, S.; Pislewski, N.; Fuel 1987, 66, 1066.

54. Fantazzini, P.; Brown, R. J. S.; Concepts Magn. Reson. 2005, 27A, 122.

55. Evdokimov, I.; Eliseev, N.; Akhmetov, B.; Fuel 2006, 85, 1465. 
56. Kershaw, J. R.; Black, K. J. T.; Jaeger, H. K.; Willing, R. I.; Hanna, J. V.; Carbon 1995, 33, 633.

57. Singer, L. S.; Lewis, I. C.; Greike, R. A.; Mol. Cryst. Liq. Cryst. 1986, 132, 65 .

58. Singer, L. S.; Lewis, I. C.; J. Phys. Chem. 1987, 91, 2408.

59. Bermejo, J.; Menéndez, R.; Fernández, A. L.; Granada, M.; Suelvez, I.; Herod, A. A.; Kandiyoti, R.; Fuel 2001, 80, 2155.
60. Lewis, I. C.; Fuel 1987, 66, 1527.

Submitted: January 23, 2012 Published online: June 28, 2012

FAPESP has sponsored the publication of this article. 